\title{
P-102
}

\section{Theoretical Evaluation on the Performance of TBHQ and BHA in Inhibiting the Autoxidation of Linoleic Acid-Rich Vegetable Oils}

\author{
Isrina Mohamad Saleh", Jurifah Ariffin and Ku Halim Ku Bulat \\ Department of Chemical Sciences, Faculty of Sciences and Technology, Universiti Malaysia Terengganu, 21030, Kuala \\ Terengganu, Terengganu Darul Iman, Malaysia; E-mail: anakibu88@yahoo.com
}

The aim of this paper is to disclose the major physical parameters responsible in determining the effectiveness of TBHQ (1) and BHA (2) as a hydroperoxyl C9-OO methyl linoleate radical (3) scavenger. In this study, Gaussian 09 software package at the theoretical level of DFT B3LYP/6-31G $(\mathrm{d}, \mathrm{p})$ were used to evaluate the physical parameters of antioxidants and the complexes formed with hydroperoxyl methyl linoleate radical of $\mathrm{C} 9-\mathrm{OO}$ such as SCF energy, hydrogen bonding strength, and the O-H bond order of antioxidants. Results of the geometry optimization combined with Natural Bond Orbital analyses of antioxidants and their complexes revealed that even though the hydrogen bonding with BHA is stronger than with TBHQ ( $\mathrm{E}_{\mathrm{BHA}}=31.9043$ $\mathrm{kJ} / \mathrm{mol}$; $\mathrm{E}_{\mathrm{TBHQ}}=31.6793 \mathrm{~kJ} / \mathrm{mol}$ ), but the $\mathrm{O}-\mathrm{H}$ sigma bond order of TBHQ is about the same as of $\mathrm{BHA}(\mathrm{TBHQ}=0.6731$; $\mathrm{BHA}=0.6736$ ). These findings are in agreement with previously reported experimental results where TBHQ performs better than or equally as good as BHA. 